\title{
Desempenho produtivo e perfil de ácidos graxos do leite de vacas que receberam níveis crescentes de óleo de girassol em dietas à base de capim-elefante
}

\author{
[Productive performance and fatty acid composition of milk from dairy cows fed increasing \\ levels of sunflower oil in elephant-grass based diets] \\ C.G.S. Ribeiro ${ }^{1}$, F.C.F. Lopes $^{1}$, M.A.S. Gama ${ }^{1}$, M.J.F. Morenz ${ }^{1}$, N.M. Rodriguez ${ }^{2}$ \\ ${ }^{1}$ Embrapa Gado de Leite - Juiz de Fora, MG \\ ${ }^{2}$ Escola de Veterinária - UFMG - Belo Horizonte, MG
}

\begin{abstract}
RESUMO
Este experimento teve como objetivo principal avaliar as alterações no perfil de ácidos graxos do leite decorrentes do fornecimento de diferentes níveis de óleo de girassol (OG) para vacas leiteiras alimentadas com dietas completas à base de capim-elefante. Doze vacas da raça Holandesa receberam quatro níveis de OG na dieta $(0 ; 1,3 ; 2,5$ e $3,7 \%$ da MS) em delineamento quadrado latino 4 x 4 . Não houve efeito $(P>0,05)$ dos níveis de OG sobre o consumo de MS, a produção de leite ou os teores de sólidos do leite. Por outro lado, o perfil de ácidos graxos (AG) do leite foi amplamante modificado com a inclusão de OG na dieta, e observou-se redução $(\mathrm{P}<0,0001)$ dos teores dos AG de cadeia curta e média, elevação dos teores de ácido oleico $(\mathrm{P}<0,0001)$, dos isômeros de ácido linoleico conjugado, em especial do ácido rumênico $(\mathrm{P}<0,0001)$ e da relação entre os ácidos graxos hipo e hipercolesterolêmicos $(\mathrm{P}<0,0001)$. Apesar da maior ingestão diária de ácido linoleico $(\mathrm{P}<0,01)$ com o aumento do nível de OG na dieta, sua concentração na gordura do leite não foi alterada. Isso indica extensiva bio-hidrogenação ruminal deste $A G$ no rúmen, o que é compatível com o aumento $(\mathrm{P}<0,0001)$ da concentração de ácido esteárico e dos AG C18:1 trans, especialmente do vacênico, na gordura do leite. Em geral, os resultados observados no presente estudo indicam que a inclusão de até 3,7\% de OG em dietas completas de vacas leiteiras à base de capim-elefante promove melhoria da qualidade nutricional da gordura do leite, sem comprometimento do desempenho produtivo dos animais.
\end{abstract}

Palavras-chave: ácido linoleico conjugado, consumo, manejo alimentar, Pennisetum purpureum, TMR

\begin{abstract}
This study aimed to evaluate the effects of different levels of sunflower oil (SO) (0, 1.3, 2.5 and 3.7\% of diet DM) on nutrient intake, milk production, milk composition, and fatty acid (FA) composition of milk and plasma from dairy cows fed elephant-grass based diets. Twelve Holstein cows were divided into three groups and received the dietary treatments in a $4 \times 4$ Latin-square design. Oleic, linoleic and $\alpha$-linolenic acid intakes increased linearly $(P<0.001)$ by adding $S O$ to the diets. The reduction $(P<0.0001)$ in odd and branched chain FA in milk fat from cows fed SO suggests that rumen microbial growth has been inhibited to some extent. Feeding up to $3.7 \%$ of SO in chopped elephantgrass-based diets improved the nutritional quality of milk fat, which was associated with the following changes in milk fatty acid composition: reduction $(P<0.0001)$ of short and medium chain saturated FA contents, increase in oleic acid and rumenic acid contents $(P<0.0001)$, and increase $(P<0.0001)$ in hypo:hypercholesterolemic FA ratio. Overall, these results indicate that including up to $3.7 \%$ SO in elephant-grass based-diets improves the nutritional quality of milk fat from dairy cows without causing any detrimental effects on production paramaters.
\end{abstract}

Keywords: conjugated linoleic acid, feed management, intake, Pennisetum purpureum, TMR

\section{INTRODUÇÃO}

Inúmeros trabalhos foram realizados com o objetivo de alterar a composição da gordura láctea, tornando-a mais adequada ao consumo humano (Gama et al., 2008). Nesse sentido, com foco na redução do risco de doenças cardiovasculares, tem-se buscado a diminuição

Recebido em 23 de maio de 2013

Aceito em 18 de dezembro de 2013

E-mail: bacaribeiro@ig.com.br 
dos teores dos ácidos graxos (AG) saturados de cadeia média e o incremento da concentração do ácido oleico (C18:1 cis-9) no leite (Dewhurst et al., 2006). Por suas propriedades anticarcinogênicas tem sido também alvo das pesquisas elevar as concentrações dos ácidos linoleicos conjugados (CLA), cujo principal isômero presente no leite bovino é o ácido rumênico (C18:2 cis-9, trans-11), bem como de seu precursor na glândula mamária, o ácido vacênico (C18:1 trans-11) (Dewhurst et al., 2006).

A suplementação de dietas de vacas leiteiras com fontes lipídicas de origem vegetal ricas em ácidos linoleico e/ou $\alpha$-linolênico tem potencial para alterar positivamente o perfil de AG da gordura do leite. Na maioria dos trabalhos em que se demonstrou esse potencial, foram utilizadas espécies forrageiras frescas de ciclo fotossintético $\mathrm{C} 3$, ou forrageiras $\mathrm{C} 4$, fornecidas, principalmente, sob a forma de fenos e silagens. Nos processos de fenação e ensilagem, podem ocorrer perdas oxidativas de AG poliinsaturados, sobretudo $\alpha$-linolênico (Dewhurst et al., 2006), que, nas plantas forrageiras, é o principal substrato lipídico para formação do ácido vacênico via processos de biohidrogenação $(\mathrm{BH})$ no rúmen, e subsequente dessaturação para ácido rumênico na glândula mamária. Por esta razão, o leite de vacas alimentadas com forrageiras fornecidas frescas apresenta potencialmente maior relação de AG insaturados:saturados, maiores concentrações de AG poli-insaturados e de CLA que o obtido do leite de vacas que receberam dietas baseadas em forragens conservadas (Gama et al., 2008). Entretanto, não há informação na literatura sobre as alterações no perfil de ácidos graxos do leite decorrentes da inclusão de óleo vegetal em dietas completas à base de forrageiras tropicais.

O objetivo deste experimento foi avaliar os efeitos da inclusão de níveis crescentes de óleo de girassol em dietas à base de capim-elefante picado, fornecido a vacas primíparas Holandesas, sobre o consumo de nutrientes, a produção e a composição do leite, sobre os parâmetros plasmáticos e o perfil de AG do leite e do plasma desses animais.

\section{MATERIAL E MÉTODOS}

Foram utilizadas 12 vacas primíparas da raça Holandesa, com 95 \pm 25 dias de lactação, produção de $16,5 \pm 2,8 \mathrm{~kg}$ de leite/dia e peso de $448 \pm 35 \mathrm{~kg}$, as quais foram alojadas em curral do tipo free-stall. Os animais foram distribuídos em três quadrados latinos (QL) $4 \times 4$, sendo cada fase do QL constituída por 10 dias de período de adaptação às dietas e cinco para coletas de dados e amostras. Os tratamentos experimentais oferecidos, com base de MS, foram: controle capim-elefante picado + concentrado sem adição de óleo de girassol (OG); 1,3\% OG - capimelefante picado + concentrado com adição de 1,3\% de OG; $2,5 \%$ OG - capim-elefante picado + concentrado com adição de $2,5 \%$ de OG; $3,7 \%$ OG - capim-elefante picado + concentrado com adição de $3,7 \%$ de OG (Tab. 1).

Tabela 1. Formulação e composição química (\% da matéria seca) das dietas experimentais

\begin{tabular}{lcccc}
\multirow{2}{*}{ Ingredientes (\% da matéria seca) } & \multicolumn{4}{c}{ Dietas } \\
\cline { 2 - 5 } & Controle & $1,3 \%$ OG & $2,5 \%$ OG & $3,7 \%$ OG \\
\hline Capim-elefante & 67,4 & 67,6 & 67,5 & 66,9 \\
Milho moído & 8,9 & 7,9 & 7,3 & 6,8 \\
Farelo de soja & 13,6 & 14,1 & 14,1 & 14,5 \\
Polpa cítrica & 8,9 & 7,8 & 7,3 & 6,7 \\
Núcleo vitamínico-mineral & 1,3 & 1,3 & 1,3 & 1,3 \\
Óleo de girassol & 0,00 & 1,28 & 2,50 & 3,74 \\
Composição química (\% da MS) & & & & 30,8 \\
Matéria seca (MS) & 28,7 & 29,8 & 29,5 & 12,4 \\
Proteína bruta (PB) & 12,4 & 12,8 & 12,1 & 53,5 \\
Fibra em detergente neutro (FDN) & 53,2 & 53,4 & 53,5 & 5,1 \\
Extrato etéreo (EE) & 1,6 & 3,0 & 4,2 & 1,68 \\
Energia líquida de lactação (Mcal/kg) ${ }^{2}$ & 1,51 & 1,57 & 1,62 & \\
\hline Valores referentes aos resultados de análise. ${ }^{2}$ Valores estimados pelo SPARTAN (Michigan State University, versão \\
2.0).
\end{tabular}


As dietas foram fornecidas na forma de mistura completa (Total mixed ration - TMR) ad libitum (10\% de sobras), uma vez ao dia, logo após a ordenha da manhã (oito horas), em cochos cobertos dotados de portões eletrônicos do tipo calan-gate (American Calan Inc., Northewood, $\mathrm{NH}$, USA). O consumo individual de alimentos foi determinado nos cinco dias de coleta de cada fase do QL. O capim-elefante (Pennisetum purpureum Schum. cv. Napier) foi cortado a cada dois dias, com idade média de, aproximadamente, 70 dias $(23,7 \%$ de MS; 5,9\% de PB; $75,8 \%$ de FDN e 55,8\% de digestibilidade in vitro da MS). O preparo dos concentrados, formulados com fubá de milho, farelo de soja, polpa cítrica, óleo de girassol e núcleo vitamínico-mineral, ocorreu a cada 14 dias.

As ordenhas foram feitas mecanicamente, duas vezes ao dia (às seis e às 14 h) e a produção de leite registrada diariamente. Nos cinco dias de coleta de cada fase do QL, foram realizadas amostragens do capim-elefante, dos concentrados, das dietas completas e das respectivas sobras individuais, que se transformaram em compostos representativos da fase do QL a que se referem e por vaca por fase do QL (sobras individuais). As amostras foram armazenadas a $-10^{\circ} \mathrm{C}$ e, depois de descongeladas, foram pré-secadas em estufa com circulação de ar a $55^{\circ} \mathrm{C}$ por 72 horas, e moídas a $1 \mathrm{~mm}$. Posteriormente, foram analisadas quanto aos teores de MS, PB, EE e FDN segundo AOAC (Association..., 1990). Amostras do capimelefante picado, dos concentrados e de seus ingredientes também foram analisadas quanto ao perfil de AG segundo o método oficial 996.06, da AOAC (Association..., 1990). A identificação dos ésteres metílicos foi realizada por comparação dos tempos de retenção com padrões da NU-CHEK (Elysian, IL, USA). O teor de cada AG foi calculado utilizando-se o peso do padrão interno e os fatores de conversão do método 996.06 (Association..., 1990).

As produções de leite foram registradas nos períodos de coleta de cada fase do QL. A produção de leite corrigida (PLC) para 3,5\% de gordura foi calculada segundo Sklan et al. (1992). Foram coletadas também amostras com o objetivo de se analisar a composição físicoquímica do leite (gordura, proteína, lactose e sólidos totais). Essas análises foram realizadas por espectrometria no infravermelho médio, no
Laboratório de Qualidade do Leite da Embrapa Gado de Leite (Juiz de Fora, MG), no equipamento Bentley 2000 (Bentley Instruments Inc., Chaska, Minnesota, USA), conforme método oficial da International Dairy Federation (International..., 2000). No primeiro dia de coletas de cada fase do QL, também foram obtidas amostras individuais de leite visando à determinação do perfil de AG no Laboratório de Cromatografia da Embrapa Gado de Leite (Juiz de Fora, MG). A extração lipídica das amostras de leite baseou-se no procedimento proposto pela AOAC (Official Method 985.05). A obtenção dos AG metil-éster ocorreu de acordo com Christie (1982), com modificações (Chouinard et al., 1999). A concentração de cada AG foi calculada a partir da multiplicação da relação das suas áreas sob as curvas (picos) em relação à área total do cromatograma (\%) pela produção diária de gordura total.

Amostras de sangue foram coletadas após a ordenha da manhã do último dia de coletas de cada fase dos QLs utilizando tubos contendo solução de EDTA-K ${ }_{3}$ como anticoagulante. Essas amostras foram imediatamente centrifugadas ( $1.500 \mathrm{~g}$ por $15 \mathrm{~min}$ ) para separação do plasma. As alíquotas destinadas à identificação do perfil de AG foram acondicionadas em microtubos (2mL) com tampa, previamente identificados, e congeladas a $-10^{\circ} \mathrm{C}$. A análise qualitativa dos AG plasmáticos seguiu o procedimento de transmetilação direta (one step) proposto por Masood et al. (2005). A determinação dos AG nas amostras de plasma foi realizada no Laboratório de Cromatografia da Embrapa Gado de Leite (Juiz de Fora, MG). A identificação dos ésteres metílicos dos AG do leite ocorreu de forma semelhante à dos alimentos e leite. Os resultados de consumo e digestibilidade de nutrientes, produção de leite, composição e perfil de AG do plasma e do leite foram analisados por meio de modelos mistos, utilizando-se o procedimento MIXED do SAS, versão 9.0 $(\mathrm{P}<0,05)$. Foram considerados efeitos fixos os níveis de inclusão do OG nas dietas e como efeitos aleatórios período, vaca, vaca (QL) e QL. Os efeitos linear e quadrático foram analisados por contrastes ortogonais utilizando o comando CONTRAST do SAS, versão 9.0. Os procedimentos experimentais empregados foram aprovados pelo Comitê de Ética em Experimentação Animal da UFMG (Protocolo CETEA 280/2010). 


\section{RESULTADOS E DISCUSSÃO}

A inclusão de diferentes níveis de OG à dieta não influenciou o consumo diário da matéria seca (MS) $(\mathrm{P}>0,05)$ tanto em kg/dia como em relação ao peso vivo (Tab. 2).

Como a relação volumoso:concentrado das dietas oferecidas permaneceu fixa em 67:33 e a contribuição de gordura do capim-elefante na dieta foi baixa, pode-se afirmar que a variação observada no perfil dos AG consumidos é reflexo direto do aumento da proporção do $\mathrm{OG}$ na dieta. Os consumos de ácido oleico (C18:1 cis-9), linoleico (C18:2 cis-9 cis-12) e $\alpha$ linolênico (C18:3 cis-9 cis-12 cis-15) elevaramse linearmente $(\mathrm{P}<0,001)$ com a adição de $\mathrm{OG}$ às dietas, com destaque para os aumentos de $473 \%$ e $328 \%$ observados para o ácido linoleico e o ácido oleico, respectivamente. Elevações tão substanciais se explicam pela alta proporção desses AG na composição do OG $(19,1 ; 66,1$; e $0,70 \mathrm{~g} / 100 \mathrm{~g}$ de $\mathrm{AG}$ totais de ácido oleico, linoleico e linolênico, respectivamente).

Tabela 2. Consumo, desempenho produtivo e composição do leite de vacas primíparas da raça Holandês alimentadas com dietas à base de capim-elefante picado, suplementadas com 0 (controle); 1,3; 2,5 e 3,7\% de óleo de girassol (OG) na matéria seca total

\begin{tabular}{|c|c|c|c|c|c|c|c|}
\hline \multirow[t]{2}{*}{ Variável } & \multicolumn{4}{|c|}{ Inclusão de OG (\% da MS) } & \multirow[t]{2}{*}{$\mathrm{EPM}^{1}$} & \multicolumn{2}{|c|}{ Valor de $\mathrm{p}$} \\
\hline & 0,0 & 1,3 & 2,5 & 3,7 & & $\mathrm{~L}$ & Q \\
\hline \multicolumn{8}{|l|}{ Consumo de MS } \\
\hline $\mathrm{kg} / \mathrm{d}$ & 10,8 & 11,5 & 10,8 & 11,1 & 0,3551 & 0,9545 & 0,4230 \\
\hline$\%$ Peso vivo & 2,44 & 2,55 & 2,46 & 2,51 & 0,0908 & 0,5499 & 0,6024 \\
\hline \multicolumn{8}{|l|}{ Consumo de AG (g) } \\
\hline $\mathrm{C} 18: 1$ cis -9 & 20,3 & 48,2 & 68,5 & 86,9 & 1,8884 & $<0,0001$ & 0,0017 \\
\hline $\mathrm{C} 18: 2$ cis-9 cis-12 & 48,1 & 139,3 & 208,2 & 275,6 & 5,8736 & $<0,0001$ & 0,0084 \\
\hline C18:3 cis-9 cis -12 cis -15 & 19,2 & 21,8 & 21,2 & 22,3 & 0,6476 & 0,0001 & 0,1045 \\
\hline $\operatorname{PLC}^{2}(\mathrm{~kg} / \mathrm{d})$ & 14,5 & 14,9 & 14,5 & 15,0 & 1,3858 & 0,5335 & 0,8959 \\
\hline Eficiência produtiva ${ }^{3}$ & 1,34 & 1,29 & 1,35 & 1,36 & 0,0948 & 0,5510 & 0,5005 \\
\hline Teores de gordura $(\%)$ & 3,36 & 3,51 & 3,56 & 3,59 & 0,0958 & 0,0015 & 0,1978 \\
\hline Teores de proteína (\%) & 2,72 & 2,73 & 2,74 & 2,72 & 0,0792 & 0,7556 & 0,4113 \\
\hline Teores de lactose $(\%)$ & 4,30 & 4,32 & 4,27 & 4,29 & 0,0967 & 0,1984 & 0,8937 \\
\hline Teores de $\operatorname{EST}^{4}(\%)$ & 11,34 & 11,51 & 11,51 & 11,52 & 0,1414 & 0,0203 & 0,0961 \\
\hline \multicolumn{8}{|l|}{ Produção (kg/dia) } \\
\hline gordura & 0,499 & 0,523 & 0,513 & 0,530 & 0,0496 & 0,2539 & 0,8491 \\
\hline proteína & 0,403 & 0,403 & 0,391 & 0,405 & 0,0292 & 0,9027 & 0,5431 \\
\hline lactose & 0,642 & 0,646 & 0,619 & 0,642 & 0,0689 & 0,7517 & 0,5988 \\
\hline EST & 1,687 & 1,716 & 1,659 & 1,715 & 0,1616 & 0,8899 & 0,7744 \\
\hline
\end{tabular}

${ }^{1}$ Erro-padrão da média. ${ }^{2}$ PLC: produção de leite corrigida para $3,5 \%$ gordura. ${ }^{3}$ Eficiência produtiva $=$ produção de leite $(\mathrm{kg}) /$ consumo de MS (kg). ${ }^{4}$ EST: extrato seco total.

O aumento dos níveis de OG na dieta causou incremento linear dos teores de gordura $(\mathrm{p}=0,0015)$ e de extrato seco total $(\mathrm{p}=0,0203)$, sem, no entanto, influenciar $(\mathrm{P}>0,05)$ os teores dos demais componentes do leite. A ausência de influência $(\mathrm{P}>0,05)$ dos tratamentos sobre as variáveis referentes à produção de leite está coerente com o comportamento do consumo diário de MS. Apesar de a adição de OG não ter causado efeito sobre o teor de lactose $(\mathrm{P}>0,05)$, os seus valores absolutos ficaram no limite inferior $(4,3 \%)$ estabelecido pelo Ministério da Agricultura, Pecuária e Abastecimento (Mapa), via Instrução Normativa $n^{\circ} 62$ (Brasil, 2011). A IN 62 determina que os teores de lactose, gordura, proteína e extrato seco total sejam superiores a 4,3; 3,0; 2,9 e $11,4 \%$, respectivamente. Nem o teor nem a produção diária de proteína do leite foram influenciados ( $\mathrm{P}>0,05)$ pelos diferentes níveis de adição de OG nas dietas. Entretanto, os valores absolutos observados (próximos a 2,7\%) ficaram aquém do valor mínimo estabelecido pela IN 62. Não há como sugerir que a microbiota ruminal tenha sofrido ação inibitória pelo $\mathrm{OG}$ a ponto de comprometer o desenvolvimento populacional e reduzir o aporte de aminoácidos (AA) à glândula mamária, já que também foram oferecidas dietas com baixos níveis de gordura $(1,6 \%$ e $3,0 \%$ de EE, no caso do tratamento controle e $1,3 \%$ de 
OG, respectivamente). Assim, os dados disponíveis no presente experimento não permitem confirmar se realmente houve comprometimento da microbiota pela ação do OG ou se as exigências proteicas, do animal ou dos microrganismos, foram comprometidas.

A suplementação de dietas com ingredientes ricos em AG poli-insaturados de cadeia longa, especialmente em ácido linoleico e $\alpha$-linolênico, tende a reduzir a síntese de novo de AG na glândula mamária e, consequentemente, o teor e a secreção diária de gordura no leite. No entanto, observou-se elevação $(p=0,0015)$ de $6,8 \%$ no teor de gordura do leite. Tal comportamento pode ser explicado pela ação simultânea de diversos fatores: o incremento da ingestão de gordura permite que maiores quantidades de $\mathrm{AG}$ sejam absorvidas e aportem à glândula mamária, aumentando, assim, a secreção de gordura no leite; a elevada relação V:C utilizada e a alta concentração de FDN do capim-elefante (dados não apresentados) certamente evitaram queda de $\mathrm{pH}$ ruminal e consequente formação dos isômeros de CLA trans-10 cis-12, que é o principal AG responsável pela síndrome da depressão do teor de gordura do leite; apesar de o CLA trans-10 cis-12 e de os demais inibidores da lipogênese mamária estarem presentes na gordura das amostras avaliadas, eles apresentaram concentrações baixas $(<0,022 \mathrm{e}$ $<0,086 \mathrm{~g} / 100 \mathrm{~g}$ de $\mathrm{AG}$ totais, respectivamente; Tab. 3), concentrações estas aparentemente incapazes de agir de forma deletéria sobre a síntese de novo de AG. Os teores de extrato seco total do leite se elevaram $(\mathrm{p}=0,02)$ cerca de $1,6 \%$ - entre o grupo controle e o que recebeu $3,7 \%$ de OG - em resposta ao aumento dos teores de gordura e à manutenção dos seus outros constituintes lácteos. $\mathrm{O}$ valor absoluto do tratamento controle foi inferior ao valor mínimo exigido pela IN $n^{-}$62. Esse comportamento se explica pelos relativamente baixos teores de proteína e lactose observados (Tab. 2). A Tab. 3 apresenta as concentrações dos principais AG presentes no plasma dos animais utilizados no presente experimento.

Tabela 3. Concentração (g/100g de AG totais) de AG no plasma de vacas primíparas da raça Holandês alimentadas com dietas à base de capim-elefante picado, suplementadas com 0 (controle); 1,3; 2,5 e 3,7\% de óleo de girassol (OG) na matéria seca total

\begin{tabular}{|c|c|c|c|c|c|c|c|}
\hline \multirow{2}{*}{ Ácidos graxos } & \multicolumn{4}{|c|}{ Inclusão de OG (\% da MS) } & \multirow{2}{*}{$\mathrm{EPM}^{1}$} & \multicolumn{2}{|c|}{ Valor de $\mathrm{p}$} \\
\hline & 0,0 & 1,3 & 2,5 & 3,7 & & $\mathrm{~L}$ & $\mathrm{Q}$ \\
\hline C18:0 & 42,872 & 39,643 & 39,695 & 39,326 & 1,0005 & 0,0046 & 0,0792 \\
\hline C18:1 trans -11 & 0,325 & 0,529 & 0,801 & 1,120 & 0,0600 & $<0,0001$ & 0,6191 \\
\hline $\mathrm{C} 18: 1$ cis $-9+$ trans -15 & 5,144 & 6,187 & 6,200 & 6,536 & 0,3657 & 0,0009 & 0,1746 \\
\hline $\mathrm{C} 18: 2$ cis -9 cis -12 & 12,504 & 15,132 & 15,621 & 15,780 & 0,6469 & 0,0001 & 0,0258 \\
\hline C18:3 cis -9 cis -12 cis -15 & 0,920 & 0,915 & 0,872 & 0,844 & 0,0610 & 0,1680 & 0,7586 \\
\hline
\end{tabular}

${ }^{1}$ Erro-padrão da média.

As concentrações plasmáticas dos ácidos esteárico, vacênico, oleico, linoleico e $\alpha$ linolênico são mais intensamente moduladas pela bio-hidrogenação ruminal. Segundo Loor et al. (2002), o ácido esteárico tende a ser o AG predominante no plasma, especialmente em animais que consomem dietas suplementadas com óleos vegetais ricos em ácidos oleico e linoleico e cuja atividade ruminal dos microrganismos fibrolíticos não tenha sido comprometida. Corroborando o relatado por esses autores, o ácido esteárico foi o AG que apresentou as maiores concentrações plasmáticas (Tab. 3). Entretanto, observou-se redução linear $(\mathrm{p}=0,0046)$ nas suas concentrações à medida que o consumo de OG se elevou. Isto sugere que, apesar dos elevados consumos do ácido esteárico e de seus precursores (ácido linoleico e $\alpha$ linolênico), a taxa de BH ruminal e, em especial, o último passo feito pelas bactérias do Grupo B provavelmente tenha sido inibida, reduzindo sua síntese e permitindo o maior acúmulo de ácido vacênico. Um dos motivos dessa inibição pode ter sido o alto aporte de ácidos graxos poliinsaturados (AGPI) no rúmen, o qual causou ação deletéria à microbiota e, consequentemente, redução na atividade microbiana (Bauman et al., 2003). A tempo, o Grupo A é formado por espécies de bactérias ruminais extremamente eficientes em hidrogenar os AG poliinsaturados livres, tendo como principal produto intermediário o ácido rumênico (CLA cis-9 trans-11) e, como final, o ácido vacênico (C18:1 trans-11), e o Grupo B são as únicas bactérias 
isoladas no rúmen capazes de converter AGPI a ácido esteárico (C18:0) (Harfoot e Hazlewood, 1988). Os teores plasmáticos do ácido oleico elevaram-se linearmente $(\mathrm{p}=0,0009)$ com o incremento de $\mathrm{OG}$ na dieta (Tab. 3). Esse aumento é reflexo, sobretudo, do aumento do seu consumo diário e do fato de este AG ser menos bio-hidrogenado no rúmen se comparado com os AGPI. Já os teores plasmáticos do ácido linoleico apresentaram comportamento quadrático $(\mathrm{p}=0,0001)$ com o incremento de $\mathrm{OG}$ na dieta. Um dos responsáveis por esse comportamento foi $\mathrm{o}$ alto aporte dietético desse $\mathrm{AG}$ no rúmen (Tab. 1) e a consequente redução da atividade dos microrganismos responsáveis pela sua $\mathrm{BH}$ (Grupos A e B) (Bauman et al., 2003).

O consumo de dietas suplementadas com os AG poli-insaturados linoleico e $\alpha$-linolênico, de modo geral, promove incremento no fluxo e na absorção intestinal de AG intermediários da $\mathrm{BH}$ ruminal, com destaque para o ácido vacênico, precursor na síntese de CLA cis-9 trans-11 na glândula mamária. No presente experimento, a concentração plasmática do vacênico elevou-se $(\mathrm{P}<0,0001)$ com o incremento de OG na dieta (Tab. 3). O aumento de $344 \%$ nos teores plasmáticos do ácido vacênico, considerando-se as dietas sem e com $3,7 \%$ de inclusão de OG, indica que houve expressiva taxa de $\mathrm{BH}$ dos ácidos linoleico e $\alpha$-linolênico consumidos. As concentrações dos isômeros de CLA, em especial do CLA cis-9 trans-11, ficaram abaixo da concentração mínima detectável pelo método de análise plasmática utilizado, o que significa que praticamente a totalidade desse isômero de CLA secretada no leite foi sintetizada na glândula mamária.

Os somatórios dos AG de cadeias curta (C4:0 a C10:0) e média (C12:0 a $\mathrm{C} 16: 0)$ tiveram suas concentrações linearmente reduzidas $(\mathrm{P}<0,0001)$ na gordura do leite com a inclusão crescente de OG nas dietas (Tab. 4). O teor do ácido palmítico, principal AG de cadeia média da gordura do leite, e o somatório das concentrações dos AG saturados de cadeia média foram reduzidos $\quad(\mathrm{P}<0,0001), \quad$ comparando-se os tratamentos sem inclusão e com $3,7 \%$ de OG. Esse comportamento sugere que a síntese de novo de AG na glândula mamária tenha sido comprometida e que o aumento dos teores de gordura do leite (Tab. 2) tivesse sido causado pelo maior aporte de AG de cadeia longa na glândula mamária originado, principalmente, da dieta. Outro fator que corrobora essa hipótese é o fato de que, apesar de os inibidores da lipogênese mamária estarem presentes na gordura das amostras de leite e terem apresentado aumento $(p=0,0002)$ em razão do incremento de OG nas dietas, eles apresentaram concentrações relativamente baixas $(<0,086 \mathrm{~g} / 100 \mathrm{~g}$ de $\mathrm{AG}$ totais; Tab. 4), suficientes apenas para promover leves reduções sobre a síntese de novo dos AG de cadeias curta e média, mas insuficientes para causar impacto negativo sobre os teores de gordura no leite. Do ponto de vista da nutrição humana, a redução da síntese de novo e, consequentemente, dos teores dos AG de cadeia média no leite é extremamente interessante, visto que esses AG são tidos como responsáveis pelo aumento dos níveis plasmáticos de LDL, pelo desenvolvimento de doenças cardiovasculares, coronarianas e pelo aumento da resistência à insulina (Gidding et al., 2009).

Segundo Baldwin e Polounsky (1977), todos os AG lácteos saturados com 18 ou mais $\mathrm{C}$ na cadeia são originados da dieta. Entre eles, o ácido esteárico é o que, normalmente, apresenta os teores mais elevados no leite. As concentrações desse ácido na gordura do leite apresentaram comportamento quadrático em razão do incremento de OG nas dietas (Tab. 4). O teor de ácido esteárico na gordura láctea está associado a três fatores: i) ao consumo desse AG na dieta; ii) ao grau de $\mathrm{BH}$ por que passam os AG poli-insaturados no rúmen (Bauman et al., 2003). Essa relação ocorre porque o esteárico é o produto final desse processo. Assim, quanto maior a concentração de esteárico no leite, maior foi a ocorrência de $\mathrm{BH}$ completa sobre os $\mathrm{AG}$ poli-insaturados no rúmen. Entende-se por $\mathrm{BH}$ completa a ação das bactérias do Grupo B; iii) à atividade das enzimas desaturase presentes nas células mamárias, em especial a $\Delta^{9}$-desaturase, responsáveis pela introdução de uma dupla ligação entre os átomos 9 e 10 da cadeia carbônica do ácido esteárico. Soyeurt et al. (2008) observaram que, em média, cerca de $40 \%$ do ácido esteárico absorvido do plasma pela glândula mamária é convertido em oleico, o que faz com que mais de $50 \%$ do oleico secretado no leite bovino seja oriundo da ação da enzima desaturase. A grande variedade de fatores que influenciam o teor do ácido esteárico na gordura do leite dificulta a interpretação do seu comportamento. Entre os principais fatores 
responsáveis pelo seu aumento plasmático e lácteo, está o fato de que o seu consumo se elevou (Tab. 2) com o incremento de OG nas dietas. O incremento de OG nas dietas também acarretou elevação no consumo de ácido oleico, linoleico e $\alpha$-linolênico, substrados da $\mathrm{BH}$ ruminal e, consequentemente, da formação do ácido esteárico. Entretanto, as concentrações plasmáticas do ácido esteárico observadas foram decrescentes em razão do nível de inclusão de OG na dieta $(\mathrm{p}=0,0046)$, resultado da incorporação preferencial desse AG pelos triglicerídeos, que respondem a somente cerca de $5 \%$ dos lipídeos plasmáticos (Abughazaleh et al., 2003).

Tabela 4. Concentração (g/100g de AG totais) dos ácidos graxos da gordura do leite de vacas primíparas da raça Holandês alimentadas com dietas à base de capim-elefante picado, suplementadas com $0 ; 1,3 ; 2,5$ e 3,7\% de óleo de girassol (OG) na matéria seca

\begin{tabular}{|c|c|c|c|c|c|c|c|}
\hline \multirow{2}{*}{ Ácidos graxos } & \multicolumn{4}{|c|}{ Inclusão de OG (\% da MS) } & \multirow{2}{*}{$\mathrm{EPM}^{1}$} & \multicolumn{2}{|c|}{ Valor de $\mathrm{p}$} \\
\hline & 0,0 & 1,3 & 2,5 & 3,7 & & $\mathrm{~L}$ & $\mathrm{Q}$ \\
\hline C16:0 & 31,229 & 24,696 & 22,174 & 19,832 & 0,8060 & $<0,0001$ & $<0,0001$ \\
\hline C18:0 & 9,810 & 14,584 & 15,696 & 16,641 & 0,6698 & $<0,0001$ & $<0,0001$ \\
\hline C18:1 trans -11 & 1,835 & 3,109 & 4,387 & 5,727 & 0,2789 & $<0,0001$ & 0,1372 \\
\hline $\mathrm{C} 18: 1$ cis $-9+$ trans -15 & 21,572 & 24,807 & 26,717 & 27,082 & 0,8682 & $<0,0001$ & 0,0036 \\
\hline $\mathrm{C} 18: 2$ cis -9 cis -12 & 1,628 & 1,648 & 1,678 & 1,549 & 0,0688 & 0,4163 & 0,1920 \\
\hline $\mathrm{C} 18: 3$ cis -9 cis -12 cis -15 & 0,212 & 0,171 & 0,156 & 0,139 & 0,0097 & $<0,0001$ & 0,0415 \\
\hline CLA cis-9 trans-11 & 0,872 & 1,224 & 1,611 & 2,128 & 0,1352 & $<0,0001$ & 0,4129 \\
\hline CLA trans -9 cis -11 & 0,030 & 0,040 & 0,052 & 0,065 & 0,0070 & $<0,0001$ & 0,7526 \\
\hline CLA trans -10 cis -12 & 0,022 & 0,015 & 0,018 & 0,021 & 0,0038 & 0,9376 & 0,1657 \\
\hline$\Sigma$ Inibidores & 0,052 & 0,055 & 0,070 & 0,086 & 0,0086 & 0,0002 & 0,2941 \\
\hline$\Sigma$ Saturados pares curta & 7,864 & 7,000 & 5,949 & 5,534 & 0,1810 & $<0,0001$ & 0,1471 \\
\hline$\Sigma$ Saturados pares média & 42,449 & 33,813 & 29,858 & 26,748 & 0,9777 & $<0,0001$ & $<0,0001$ \\
\hline$\Sigma$ Saturados pares longa & 10,043 & 14,844 & 15,954 & 16,887 & 0,6737 & $<0,0001$ & $<0,0001$ \\
\hline$\Sigma$ Saturados pares total & 60,302 & 55,646 & 51,750 & 49,177 & 0,8278 & $<0,0001$ & 0,0801 \\
\hline$\Sigma \mathrm{AGCIR}^{2}$ & 5,533 & 4,679 & 4,142 & 3,769 & 0,0945 & $<0,0001$ & 0,0097 \\
\hline$\Sigma$ Monoinsaturados trans & 3,113 & 5,555 & 7,614 & 9,565 & 0,3974 & $<0,0001$ & 0,5257 \\
\hline$\Sigma$ Poli-insaturados $\omega-3$ & 0,308 & 0,242 & 0,219 & 0,195 & 0,0120 & $<0,0001$ & 0,0343 \\
\hline$\Sigma$ Poli-insaturados $\omega-6$ & 1,880 & 1,864 & 1,855 & 1,705 & 0,0714 & 0,0541 & 0,2709 \\
\hline Hipo:hiper ${ }^{3}$ & 0,516 & 0,749 & 0,916 & 1,026 & 0,0536 & $<0,0001$ & 0,0256 \\
\hline$\omega-6: \omega-3^{4}$ & 6,2 & 7,8 & 8,5 & 8,8 & 0,3197 & $<0,0001$ & 0,0355 \\
\hline
\end{tabular}

${ }^{\mathrm{T}}$ Erro-padrão da média. ${ }^{2}$ Ácidos graxos de cadeia ímpar e ramificada. ${ }^{3}$ Relação entre os AG hipocolesterolêmicos

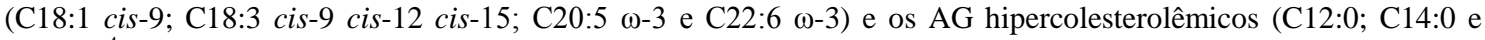
C16:0). ${ }^{4}$ Relação entre os AG $\omega-6$ e os $\omega-3$.

Dois fatores influenciam diretamente a secreção láctea de AG insaturados pelos ruminantes: o fornecimento de volumoso jovem com alta relação folha:haste e rico em tecidos metabolicamente ativos; a suplementação lipídica, em especial, com grãos ou óleos vegetais ricos em ácido oleico, linoleico ou $\alpha$ linolênico. No presente experimento, apesar da elevação dos teores do ácido esteárico, os teores dos AG saturados totais reduziram $(\mathrm{P}<0,0001)$ em cerca de $25 \%$ entre os tratamentos com inclusão de $0 \%$ e 3,7\% de OG (Tab. 4).

No OG utilizado no presente experimento, o ácido linoleico correspondeu a $66,1 \%$ dos AG totais, o que permitiu elevada diferença no consumo desse AG entre os tratamentos com 0 e $3,7 \%$ de OG. O elevado consumo de ácido linoleico está diretamente associado à secreção mamária dos AG C18:1 trans, já que a $\mathrm{BH}$ ruminal do ácido linoleico gera uma vasta gama de intermediários, entre eles os isômeros octadecenoicos trans. No presente experimento, os teores desses AG se elevaram $(\mathrm{P}<0,0001)$ com o fornecimento de OG e participaram com 10,7; 16,2; 20,0 e 23,6\% do total dos isômeros C18:1 para as dietas com $0 ; 1,3 ; 2,5$ e $3,7 \%$ de OG, respectivamente. $\mathrm{O}$ interesse pelos AG trans tem aumentado devido à sua associação com o aumento dos riscos de ocorrência de doenças coronarianas e de outras doenças crônicas (Lock e Bauman, 2011). Entre os AG trans, o vacênico 
(C18:1 trans-11) é o isômero presente em maior concentração na gordura do leite, com 1 a $10 \%$ do conteúdo total de AG (Haug et al., 2007). O principal responsável por essa variação é o tipo de dieta fornecida ao animal, uma vez que quanto maior a concentração de AGPI da dieta, maior a sua secreção na gordura láctea. Essas afirmações foram confirmadas quando se observou incremento nas concentrações plasmáticas do ácido vacênico $(\mathrm{P}<0,0001) \mathrm{em}$ razão da inclusão de OG na dieta (Tab. 3). Como reflexo, foi também observado incremento $(\mathrm{P}<0,0001)$ em seus teores lácteos com a suplementação das dietas com OG (Tab. 4).

O somatório das concentrações dos AGCIR foi reduzido linearmente $(\mathrm{P}<0,0001)$ entre os tratamentos controle e aquele com $3,7 \%$ de OG. Considerando-se o fato de que todos os AGCIR presentes na gordura do leite são sintetizados exclusivamente pelos microrganismos ruminais, pode ter havido algum comprometimento no crescimento da microbiota do rúmen. Essa afirmação é reforçada pelos baixos teores de proteína e lactose do leite (Tab. 2). Apesar da redução dos teores plasmáticos e lácteos dos AGCIR (Tab. 3 e 4, respectivamente) e dos baixos teores de proteína e lactose no leite (Tab. 3), não foram observados efeitos negativos $(\mathrm{P}>0,05)$ da inclusão de OG nas dietas sobre o consumo de MS, a produção de leite ou o teor de gordura do leite. Isto sugere que a atividade da população microbiana tenha sido reduzida a ponto de diminuir a fermentação ruminal e, consequentemente, a síntese de acetato e propionato, mas não o suficiente a ponto de comprometer a degradabilidade da dieta.

O teor lácteo dos AG $\omega-6$ permaneceu estável $(\mathrm{P}>0,05)$. Esse comportamento se explica pela estabilidade $(\mathrm{P}>0,05)$ observada na concentração láctea do ácido linoleico, AG $\omega-6$ de maior concentração (aproximadamente $89 \%$ do total). Os teores dos AG $\omega-3$ foram reduzidos $(\mathrm{P}<0,0001)$ com a inclusão de OG na dieta. No caso específico do $\alpha$-linolênico, apesar de o seu consumo ter sido crescente $(\mathrm{p}=0,0001)$ à medida que houve incremento no fornecimento de $O G$ à dieta (Tab. 2), sua concentração plasmática estável, mas com tendência $(\mathrm{p}=$ 0,0610) de redução (Tab. 3), sugere elevação no grau de $\mathrm{BH}$ com o aumento do seu aporte no rúmen. Essa mesma sugestão vale para o ácido linoleico, que, assim como o $\alpha$-linolênico, também apresentou aumento de consumo $(\mathrm{P}<0,0001)$ com a inclusão de $\mathrm{OG}$ na dieta, entretanto não apresentou variação $(\mathrm{P}>0,05)$ nos teores lácteos. A relação $\omega-6: \omega-3$ é um parâmetro utilizado para classificar a qualidade nutricional das gorduras, dos óleos e das dietas. No presente experimento, a relação $\omega-6: \omega-3$ elevou-se $(p=$ $0,0355)$ com a inclusão de OG à dieta (Tab. 4). O aumento da relação $\omega-6: \omega-3$ é indesejável do ponto de vista de saúde humana, já que, apesar de ser um AG essencial, níveis elevados de $\omega-6$ são responsáveis por desencadear uma série de disfunções fisiológicas, como a formação de trombos, de ateromas e de desordens imunológicas (Haug et al., 2007).

Foi observado incremento linear $(\mathrm{P}<0,0001)$ na concentração de ácido rumênico no leite com a inclusão de OG na dieta (Tab. 4), com aumento da ordem de $244 \%$ entre os tratamentos controle e $3,7 \%$ de OG. Para o ácido rumênico foi observado incremento linear $(\mathrm{P}<0,0001)$ na concentração de ácido vacênico no leite em razão da inclusão de OG na dieta (Tab. 4). A concentração CLA trans-10 cis-12 no leite apresentou-se estável $(\mathrm{P}>0,05)$, com valor médio de $0,019 \mathrm{~g} / 100 \mathrm{~g}$ de $\mathrm{AG}$ totais (Tab. 4). Esse valor baixo é normal, já que, segundo Griinari et al. (1998), ele pode se apresentar em níveis quase indetectáveis na gordura do leite de animais submetidos a dietas com alta relação $\mathrm{V}: \mathrm{C}$, como foi o caso do presente experimento. $\mathrm{O}$ isômero CLA trans-9 cis-11 apresentou incremento linear $(\mathrm{P}<0,0001)$ na sua concentração no leite em razão da inclusão de OG na dieta (Tab. 4). Esse aumento foi da ordem de $120 \%$ entre os tratamentos controle e com $3,7 \%$ de OG. De maneira geral, esses dois AG apresentam forte correlação negativa com os teores de gordura do leite (Perfield et al., 2007). Entretanto, no presente experimento, não se observou esse comportamento. Apesar da estabilidade das concentrações do isômero CLA trans-10 cis-12, o CLA trans-9 cis-11 elevou suas concentrações, assim como ocorreu com o teor de gordura. Esse comportamento atípico pode ser consequência dos baixos teores absolutos desses isômeros que, provavelmente, inibiram pouco a lipogênese; o suficiente para reduzir a síntese de novo de AG, mas incapaz de causar redução na secreção de gordura no leite devido ao maior aporte de gordura na glândula mamária. 


\section{CONCLUSÕES}

A suplementação de vacas leiteiras com óleo de girassol em níveis iguais ou inferiores a 3,7\% da matéria seca em dietas à base de capim-elefante picado melhorou a qualidade da gordura do leite do ponto de vista da nutrição humana. Tais benefícios foram decorrentes da redução dos teores dos AG de cadeias curta e média; da elevação dos teores de ácido oleico e dos isômeros de CLA, em especial do ácido rumênico, além da elevação dos valores absolutos da relação entre os ácidos graxos hipo e hipercolesterolêmicos.

\section{AGRADECIMENTOS}

À Fapemig e ao CNPq, pelo financiamento do trabalho.

\section{REFERÊNCIAS}

ABUGHAZALEH, A.; SCHINGOETHE, D.J.; HIPPEN, A.R. CLA and Vaccenic Acid in Rumen, Plasma, and Milk of Cows Fed Fish Oil and Fats Differing in Saturation of 18 Carbon FA. J. Dairy Sci., v.86, p.3648-3660, 2003.

ASSOCIATION of Official Analytical ChemistisAOAC. Official Methods of Analysis, 11 ed. Washington D.C.: AOAC, 1990.

BALDWIN, A.; POLOUNSKY, K.W. In: COLE, H.H.E CUPP, P.T. Reproduction in Domestic Animals. 3.ed. Acad. Press. 1977, 421p.

BAUMAN, D.E.; PERFIELD II, J.W.; DE VETH, M.J.; LOCK, A.L. New perspectives on lipid digestion and metabolism in ruminants. Proc. Cornell Nutr. Conf., p.175-189, 2003.

BRASIL - MINISTÉRIO DA AGRICULTURA, DO ABASTECIMENTO E DA REFORMA AGRÁRIA. Instrução normativa n.62, de 29/12/11. Regulamentos técnicos de produção, identidade, qualidade, coleta e transporte de leite. Brasília, DF: MAPA, Secretaria de Inspeção de Produto Animal, 2011, 24p.

CHOUINARD, P.Y.; CORNEAU, L.; SAEBO, A. et al. Milk yield and composition during abomasal infusion of conjugated linoleic acids in dairy cows. $J$. of Dairy Sci., v.82, p.2737-2745, 1999.

CHRISTIE, W.W. A simple procedure for rapid transmethylation of glycerolipids and cholesterol esters. J. Lipid Res. v.23, p.1072, 1982.

DEWHURST, R.J.; SHINGFIELD, K.J.; LEE, M.R.F. Increasing the concentrations of beneficial polyunsaturated fatty acids in milk produced by dairy cows in high-forage systems. Anim. Feed Scie. and Technol.. v.131, p.168-206, 2006.
GAMA, M.A.S.; LOPES, F.C.F.; RIGUEIRA, J.C.S. et al. Perfil de ácidos graxos e estabilidade oxidativa de manteigas oriundas de vacas recebendo óleo de soja. In: CONGRESSO BRASILEIRO DE CIÊNCIA E TECNOLOGIA DE ALIMENTOS, 21., 2008, Belo Horizonte. Anais... Belo Horizonte: sBCTA/UFMG, 2008.

GIDDING, S.S.; LICHTENSTEIN, A.H.; FAITH, M.S. et al. Implementing American Heart Association Pediatric and Adult Nutrition Guidelines. Circulation. v.119, p.1161-1175, 2009.

GRIINARI, J.M.; DWYER, D.A.; MCGUIRE, M.A. et al. Trans-octadecenoic acids and milk fat depression in lactating dairy cows. J. Dairy Sci.. v.81, p.12511261, 1998.

HARFOOT, C.G.; HAZLEWOOD, G.P. Lipid metabolism in the rumen. In: HOBSON, P.N. (Ed.) The rumen microbiol ecosystem. London: Elsevier Applied Science, p.285-322, 1988.

HAUG, A.; HØSTMARK, A.T.; HARSTAD, O.M. Bovine milk in human nutrition - a review. Lipids in Heal. and Dise., v.6, p.25, 2007.

INTERNATIONAL Dairy Federation. Determination of milfat, protein and lactose content - Guidance on the operantion of mid-infrared instruments. Brussels: IDF, 2000. 15p. IDF Standard 141C.

LOCK, A.L.; BAUMAN, D.E. Separating Milk Fats from Fiction. WCDS Advances in Dairy Technol., v.23, p.19-36, 2011.

LOOR, J.J.; HERBEIN, J.H.; POLAN, C.E. Trans 18:1 and 18:2 Isomers in Plasma and Milk Fat of Grazing Cows Fed a Grain Supplement Containing SolventExtracted. J. Dairy Sci., v.85, p.1197-1207, 2002.

MASOOD, A.; STARK, K.D.; SALEM JR, N. A simplified and efficient method for the analysis of fatty acid methyl esters suitable for large clinical studies. J. Lipid Res., v.46, p.2299-2305, 2005.

PERFIELD, J.W.; LOCK, A.L.; GRIINARI, J.M. et al. Trans-9, Cis-11 CLA Reduces Milk Fat Synthesis in Lactating Cows. J. Dairy Sci., v.90, p.2211-2218, 2007.

SKLAN, D.; ASHKENNAZI, R.; BRAUN, A. et al. Fatty acids, calcium soaps of fatty acids, and cottonseeds fed to high yielding cows. J. Dairy Sci., v.75, p.2463-2472, 1992.

SOYEURT, H.; DEHARENG, F.; MAYERES, P.; BERTOZZI, C. Variation of $\triangle 9$-Desaturase Activity in Dairy Cattle. J. Dairy Sci., v.91, p.3211-3224, 2008. 